\title{
Mismatch between electrophysiologically defined and ventriculography based theoretical targets for posteroventral pallidotomy in Parkinson's disease
}

\author{
M Merello, A Cammarota, D Cerquetti, R C Leiguarda
}

\begin{abstract}
Objectives-Over the past few years many reports have shown that posteroventral pallidotomy is an effective method for treating advanced cases of Parkinson's disease. The main differences with earlier descriptions were the use of standardised evaluation with new high resolution MRI studies and of single cell microrecording which can electrophysiologically define the sensorimotor portion of the internal globus pallidus (GPi). The present study was performed on a consecutive series of 40 patients with Parkinson's disease who underwent posteroventral pallidotomy to determine localisation discrepancies between the ventriculography based theoretical and the electrophysiologically defined target for posteroventral pallidotomy.

Methods-The tentative location of the posteroventral GPi portion was defined according to the proportional Talairach system. Single cell recording was performed in all patients. The definitive target was chosen according to the feasibility of recording single cells with GPi cell features, including the presence of motor drive and correct identification of the internal capsule and of the optic tract by activity recording and microstimulation.
\end{abstract}

Results-In all 40 patients the electrophysiologically defined sensorimotor portion of the GPi was lesioned, with significantly improved cardinal Parkinson's disease symptoms as well as levodopa induced dyskinesias, without damage to the internal capsule or optic tract. Significant differences between the localisation of the ventriculography based theoretical versus electrophysiological target were found in depth $(p<0.0008)$ and posteriority $(p<0.04)$. No significant differences were found in laterality between both approaches. Difference ranges were 8 $\mathrm{mm}$ for laterality, $6.5 \mathrm{~mm}$ for depth, and $10 \mathrm{~mm}$ for posteriority.

Conclusions-Electrophysiologically defined lesion of GPi for posteroventral pallidotomy, shown to be effective for treating Parkinson's disease, is located at a significantly different site from the ventriculography based theoretical target.

(f Neurol Neurosurg Psychiatry 2000;69:787-791)

Keywords: pallidotomy; Parkinson's disease; microrecording; globus pallidus
Over the past few years many reports have shown that posteroventral pallidotomy is an effective method for treating advanced cases of Parkinson's disease. ${ }^{1-6}$ The main differences with earlier descriptions are the use of standardised evaluation methods such as the core assessment program for intracerebral transplantation (CAPIT), ${ }^{7}$ high resolution MRI targeting, and single cell microrecording within the striatum, which can electrophysiologically define the sensorimotor portion of the internal globus pallidus (GPi).

Commonly, GPi localisation has been performed indirectly, using the anterior commissure-anterior commissure (AC-PC) line as reference, whether determined by ventriculography ${ }^{8}, \mathrm{CT}^{9}$, or MRI. ${ }^{10}$ However, due to substantial individual AC-PC line variation, target coordinates are expressed as a range, rather than as exact values. In a survey of current practice of pallidotomy within the United States, Favre et $a l^{11}$ reported the results of a questionnaire sent to different centres, of which $50 \%$ performed the procedure with microrecording and 50\% without, but neither data on the outcome nor on complications of the procedure were presented. Even though no conclusion can be drawn from such a study, it provoked the controversy over the usefulness and safety of microrecording. Those who perform microrecording argue that it remains the key to successful lesioning and the prevention of complications, helping not only with target site definition but also with the volume and shape of the lesion. ${ }^{12}$ Those who do not perform microrecording contend that it is no better than the use of macrostimulation to obtain a correctly located pallidotomy and that if it increases the risk of side effects then it should only be used for research purposes. ${ }^{13}$

The present study was carried out to determine localisation discrepancies between the ventriculography based theoretical and the electrophysiologically defined target within the sensorimotor portion of the GPi in a prospective series of patients who underwent posteroventral pallidotomy.

\section{Methods}

A consecutive series of 40 patients who underwent microguided posteroventral pallidotomy was included in the analysis. All patients met UKPDS-BB clinical criteria for idiopathic Parkinson's disease, ${ }^{14}$ had a positive response to levodopa, and presented motor fluctuations and marked dyskinesias.

Inclusion criteria for the posteroventral pallidotomy programme were basically as 
Mean (SD) UPDRS motor section and dyskinesia score values

\begin{tabular}{lllll}
\hline & State & Preoperative & Postoperative & ANOVA \\
\hline Motor score & Off & $29.4(9.6)$ & $17.9(8.6)$ & $F(1,27)=38.4 ; \mathrm{p}<0.000$ \\
& On & $14.8(9.1)$ & $11.3(7.5)$ & \\
Rigidity & Off & $2.0(1.2)$ & $1.6(1.2)$ & $F(3,69)=2.81 ; \mathrm{p}<0.04$ \\
& On & $0.8(0.8)$ & $0.7(1.1)$ & \\
Resting tremor & Off & $1.9(1.5)$ & $0.8(1.1)$ & $F(3,57)=4.28 ; \mathrm{p}<0.008$ \\
& On & $0.8(1.1)$ & $0.1(0.3)$ & \\
Bradykinesia & Off & $5(3.1)$ & $3(2.5)$ & $F(3,60)=3.74 ; \mathrm{p}<0.01$ \\
& On & $2.7(2.5)$ & $1.4(1.5)$ & \\
PIGD & Off & $5.1(2)$ & $3.2(2.1)$ & $F(1,27)=1.39 ; \mathrm{p}<0.2$ \\
& On & $3.5(1.9)$ & $2.2(2.5)$ & \\
Head dyskinesia & & $1.7(1.3)$ & $0.36(0.6)$ & $F(1,28)=25.25 ; \mathrm{p}<0.000$ \\
Trunk dyskinesia & & $1.6(1.4)$ & $0.28(0.55)$ & $F(1,28)=1.28 ; \mathrm{p}<0.2$ \\
$\begin{array}{l}\text { Ipsilateral } \\
\text { (non-operated side) }\end{array}$ & & $0.6(1.08)$ & $0.16(0.53)$ & $F(1,29)=61.3 ; \mathrm{p}<0.01$ \\
limb dyskinesia & & & & \\
$\begin{array}{l}\text { Contralateral } \\
\text { (operated side) limb }\end{array}$ & & $2.38(1.25)$ & $0.38(0.53)$ & $F(1,30)=59.6 ; \mathrm{p}<0.000$ \\
dyskinesia & & & \\
\hline
\end{tabular}

PIGD = Postural instability gait disorders.
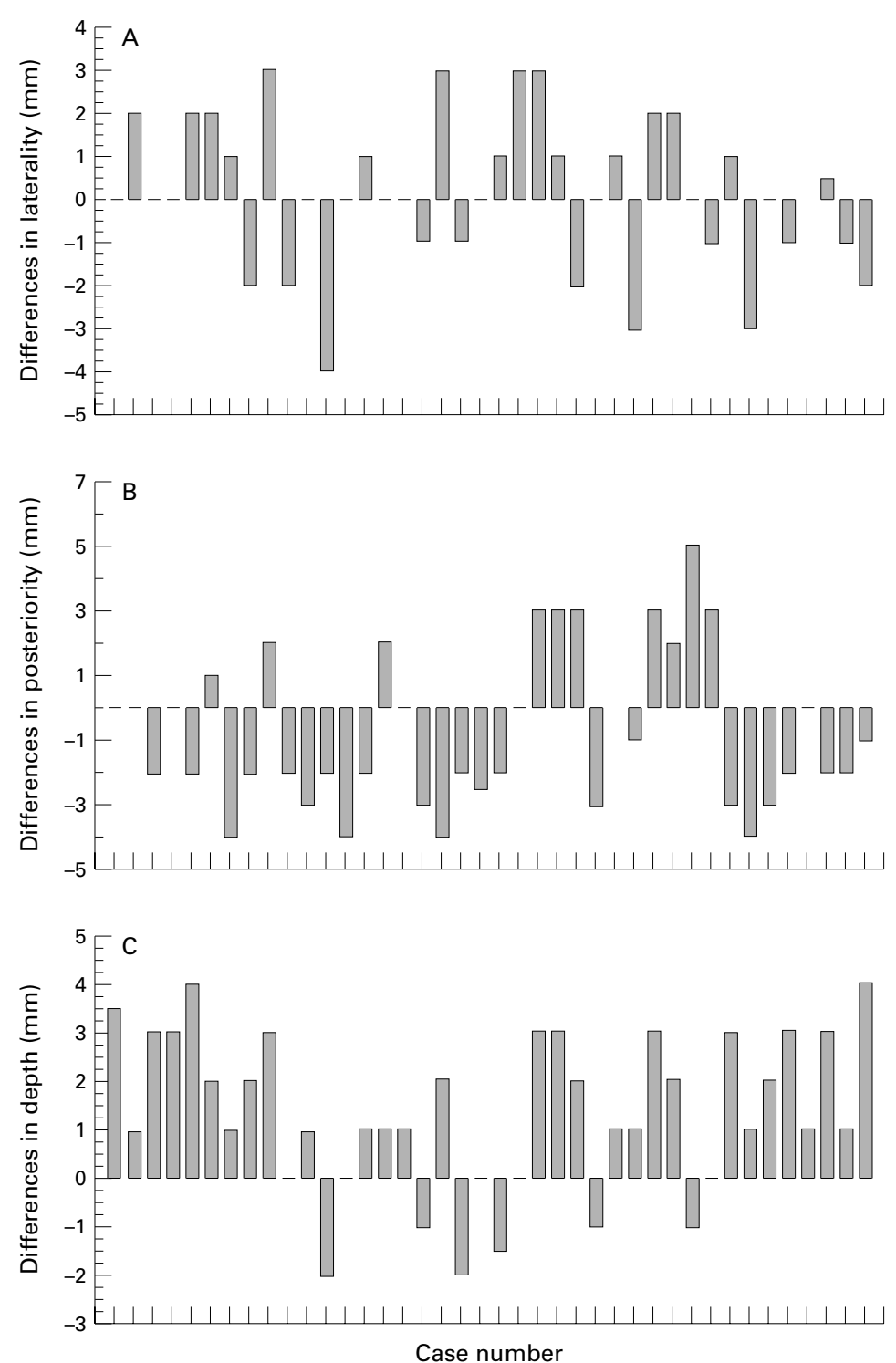

Figure 1 Bars indicate differences $(\mathrm{mm})$ between the ventriculography based theoretical and electrophysiological target for each patient. $(A)$ Laterality from midline $(x),(B)$ posteriority to $A C$ line $(y)$, and $(C)$ depth from $A C-P C$ line $(z)$. In order not to underestimate the differences because of negative and positive values, Sqr. (theoretical-electrophysiological) ${ }^{2}$ was applied as in the text. Differences in depth show a tendency of theoretical target estimation to be deeper, whereas differences in anteroposterior locality are highly variable, representing target variability rather than theoretical targeting error. follows: lack of sustained benefit from the use of antiparkinsonian medication on activities of daily living (ADL) scores; unified Parkinson's disease rating scale (UPDRS) scores with bradykinesia and rigidity predominating over resting tremor; response to levodopa complicated with severe biphasic or interdose dyskinesias noticeably interfering with the patient's quality of life; markedly asymmetric symptoms; and Hoehn and Yahr score greater than III in the on stage. Patients were evaluated and followed up according to CAPIT. Basal scores were calculated by averaging two preoperative evaluations, and postoperative scores corresponded to 1 year follow up.

For each case, anatomical and electrophysiological targets were calculated as below.

TENTATIVE TARGET PLANNING

(VENTRICULOGRAPHY BASED THEORETICAL

TARGET)

Under local anaesthesia a Talairach frame was affixed at four points. ${ }^{15}$ Ventriculography was used to identify the AC and PC, the AC-PC line, and thalamic height. The proportional Talairach lines were established according to these parameters. ${ }^{4}$ The tentative target for the initial track was calculated $2-3 \mathrm{~mm}$ ahead of the midpoint on the AC-PC line, at a depth equivalent to one quarter of the thalamic height below the AC-PC line ( 4 to $6 \mathrm{~mm}$ ) and 18-21 mm lateral to the midline.

MICRORECORDING DEFINITION OF TARGET (ELECTROPHYSIOLOGICAL TARGET)

Microrecording was made by means of a platinum/iridium $(80 \% / 20 \%)$ microelectrode with an impedance of 0.8-1.2 Megohms measured at $1000 \mathrm{~Hz}$ with glass insulation, sheathed inside a 26 gauge stainless steel tube which was itself insulated with polyamide tubing with an outer diameter of $0.625 \mathrm{~mm}$ (FHC 14TDS KM). A preamplifier (ARS-3D-1 remote probe, Atlanta, USA) was connected to a differential amplifier, impedance meter, and biphasic pulse generator (ARS-MDA4I, Atlanta, USA). The signal was amplified, isolated, and led to oscilloscopes, to a window discriminator, and to an audio equaliser. The window discriminator had different voltage levels to allow triggering pulses and to count and display firing frequencies. The signal was recorded in a high fidelity videocassette using an analog video/audio recording system (ARSDC1, Atlanta, USA) for postprocessing analysis. On line recording and raster display were monitored together with an EMG and an accelerometer signal. The number of recording tracks performed at each operation depended on: (1) the ability to identify unequivocally the putamen, GPe, and GPi; (2) the presence of motor drive (enhanced phase response to proprioceptive stimuli in GPi neurons); (3) correct identification of the internal capsule by microstimulation; and (4) correct identification of the optic tract by microstimulation and activity recording after visual stimulation. 

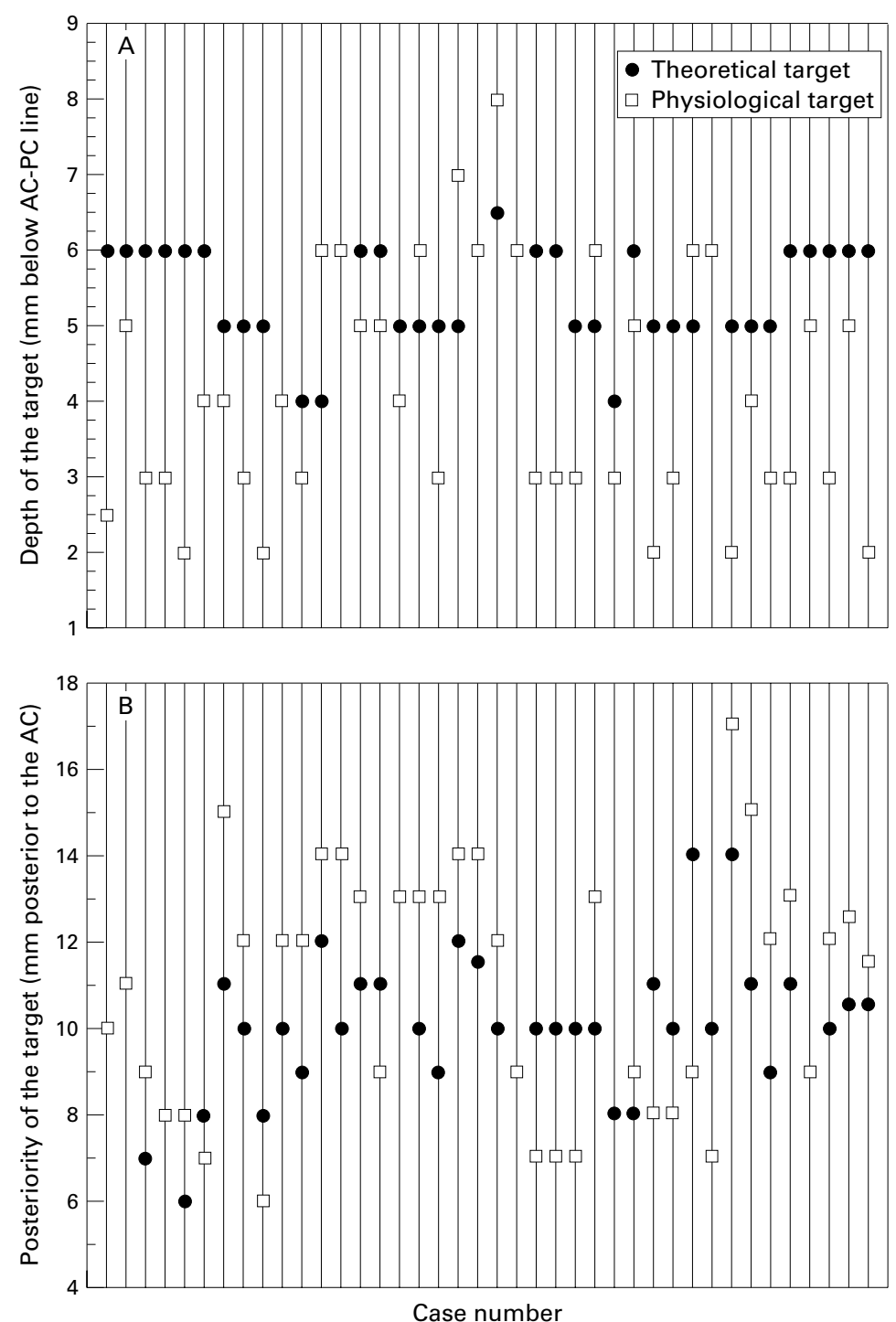

Figure 2 (A) Raw coordinates in the $x$ axis, $(B) y$ axis, and $(C) z$ axis for each patient, The $x, y$, and $z$ theoretical coordinates matched the electrophysiological coordinates in only one out of 40 patients. movements. Forty patients, 25 men and 15 women, completed 1 year postsurgical follow up after posteroventral pallidotomy treatment for Parkinson's disease. Mean age was 57.94 (SD 11.65) years, with a mean disease duration of 13.87 (SD 4.83) years. Mean Hoehn and Yahr score was 3.78 (SD 1.07) in the off state and 3.29 (SD 0.96) in the on state. Mean ADL score was 37.69 (SD 27.8) in off versus 50.25 (SD 24.3) in on. Preoperative and postoperative clinical evaluation scores are displayed in the table. No damage to the optic tract was seen in any patient. Morbidity included transient facial palsy in one patient, transient crural paresis in two, transient dysarthria in one, postoperative delirium in two, seizures in one at 2 months after surgery, postoperative pneumonia in one, subdural haematoma in one, and wound infection in one. Therefore, overall morbidity of the procedure was $14.81 \%$. Although not reported in this series, only one patient out of 75 died from an intracerebral haematoma $(1.3 \%) .{ }^{16}$

\section{DIFFERENCES IN VENTRICULOGRAPHY BASED THEORETICAL VERSUS ELECTROPHYSIOLOGICAL TARGET}

Significant differences between the localisation of the ventriculography based theoretical versus electrophysiological target were found in depth $(\mathrm{y} ; F(1,39)=26.5 ; \mathrm{p}<0.0008)$ and anteroposterior locality $(\mathrm{z} ; \quad F(1,38)=4.11$; $p<0.04)$. No significant differences were found in laterality $(\mathrm{x} ; F(1,38)=0.25 ; \mathrm{p}<0.6)$ between both approaches. Difference ranges were $8 \mathrm{~mm}$ for laterality, $6.5 \mathrm{~mm}$ for depth, and $10 \mathrm{~mm}$ for posteriority. Modes for differences in $\mathrm{z}, \mathrm{y}$, and $\mathrm{x}$ were $-2,1$, and 0 respectively (fig $1 \mathrm{~A}, \mathrm{~B}$, and C).

In 30 patients $(70 \%)$, none of the theoretical $\mathrm{x}, \mathrm{y}$, or $\mathrm{z}$ coordinates matched the electrophysiological coordinates. In five patients $(12.5 \%)$, one theoretical coordinate matched the electrophysiological coordinate, and in four patients $(10 \%)$, two coordinates. In only one patient did the theoretical target match the electrophysiological target (fig $2 \mathrm{~A}, \mathrm{~B}$, and C).

Differences were evaluated by multivariate analysis of variance (MANOVA) with post hoc paired $t$ test. All $\mathrm{p}$ values are two tailed. The threshold for significance was $p<0.05$. In order not to underestimate the range of differences between the ventriculography based theoretical and electrophysiological targets due to the presence of negative and positive gaps, an Sqr (theoretical-electrophysiological) ${ }^{2}$ was applied to all differences and mean SD range of differences calculated on this value. Difference mode was also calculated to disclose a tendency for a positive or negative value.

\section{Results}

CLINICAL OUTCOME

In all 40 patients the electrophysiologically defined sensorimotor portion of the GPi was lesioned, with significant improvement in cardinal Parkinson's disease symptoms as well as in levodopa induced involuntary

\section{Discussion}

This study highlights three main findings: (1) There is a significant individual variability in the spatial position of an atlas defined GPi target. (2) The electrophysiologically defined localisation for posteroventral pallidotomy, shown to be effective for treating Parkinson's disease, is located at a significantly different site than the ventriculography based theoretical target. (3) Differences in anteroposterior locality were highly variable, whereas in depth the theoretical target was commonly located deeper than the electrophysiological target. This may be interpreted as follows: whereas differences in anteroposterior locality are due to target variability, differences in depth are mainly attributable to a limitation of our theoretical calculation of the target according to the proportional Talairach system. These findings confirm the need for electrophysiological recording not only to improve 
target selection, but also to prevent optic tract damage that could otherwise have occurred in many of our patients when the ventriculography based target was calculated according to the Talairach proportional system.

There is general agreement within contemporary neurosurgery that the lesion in the posterior part of the GPi is the most effective in treating Parkinson's disease. ${ }^{1-6}$ Theoretically, the lesion should include the entire sensorimotor territory of the $\mathrm{GPi}$, including the neurons that give rise to the ansa lenticularis and fasciculus lenticularis. ${ }^{17}$ Careful placement of the lesion in this area is mandatory due to the vital surrounding structures. Whether or not intraoperative microrecording is necessary to perform pallidotomy safely and effectively is still a matter of controversy, despite the excellent outcomes reported by several groups ${ }^{1-6}$ Opponents to microrecording argue that this technique increases the cost of the procedure and is labour intensive, difficult to perform well, and time consuming, while providing data of little practical use. ${ }^{18} 19$ Whether or not the use of microrecording results in a higher incidence of complications is a difficult issue to address, as it is troublesome to determine whether described complications occurred during microrecording or lesion performance. In our experience with 75 procedures, the single intracerebral haematoma occurred during lesion performance rather than during microrecording ${ }^{16}$ and none of the related complications could be attributed to microrecording. Currently, the average number of tracks in our group is three to four, but it has changed with time and our learning curve. Exceptionally, in one patient more than 8 tracks were necessary for target determination, thus prolonging surgery duration to over 5 hours and exposing the patient to a greater risk of complications and fatigue. However, to perform the lesion according to the ventriculography based theoretical target would probably have resulted in a poorer surgical outcome as this patient had a significant difference between the theoretical and electrophysiologically defined targets.

Errors in target selection by ventriculography $^{20}$ and discrepancies between the electrophysiological and theoretical target when the second is calculated by ventriculography and the Talairach proportional system are greater than those found with an MRI based AC-PC calculation, ${ }^{21}$ meaning that high resolution MRI based targeting is more accurate. Our results are in agreement with those from Alterman et $a l^{2}$ showing that microrecording provides practical information for functional localisation of the target, altering the theoretical target position. We also agree with Alterman et al that microrecording should not be performed by inexperienced groups. At variance with these authors, so far we refrain from performing macrostimulation because of our confidence in GPi, optic tract and internal capsule microrecording and microstimulation.
On reviewing MRI studies of patients not included in the present series but referred to our centre with previously unsuccessful operations, we saw that patients with lesions that only partially involved GPi, or lesions spreading to the GPe, sustained less benefit than those in whom the lesion had been properly situated and this is in agreement with other previous reports. ${ }^{23}$ Vitek et al published their results on microrecording guided pallidotomy in a series of patients followed up for 18 months that showed no beneficial effect wearing off. ${ }^{1}$ This is in agreement with the results published by Lang et al, ${ }^{5}$ but at variance with those presented by Samii et al in a 2 year follow up of posteroventral pallidotomy not guided by microrecording, who reported that the beneficial effects of surgery were not sustained. ${ }^{24}$ This suggests that performance of the lesion under microelectrode guidance could also have a beneficial effect on the long term effect of surgery. Unfortunately, the only way to resolve the usefulness of microrecording in posteroventral pallidotomy is by means of a prospective randomised double blind evaluation, which has not yet been carried out.

1 Baron MS, Vitek JL, Bakay RAE, et al. Treatment of advanced Parkinson's disease by internal globus pallidotomy: 1 year results of a pilot study. Ann Neurol 1996;40:355-66.

2 Dogali M, Fazzini E, Kolodny E, et al. Stereotactic ventral pallidotomy for Parkinson's disease. Neurology 1995;45: pallidotom

3 Fazzini E, Dogali M, Sterio D, et al. Stereotactic pallidotomy for Parkinson's disease: A long-term follow-up of unilateral pallidotomy. Neurology 1997;48:1273-7.

4 Lozano A, Lang A, Galvez-Jimenez N, et al. Effect of GPi pallidotomy on motor function in Parkinson's disease. Lancet 1995;346:1383-7.

5 Lang A, Lozano A, Montgomery E, et al. Posteroventral medial pallidotomy in advanced Parkinson's disease. $N$ Engl f Med 1997;337:1036-42.

6 Merello M, Nouzeilles MI, Cammarota A, et al. Comparison of 1 year follow up evaluation of patients with indication for pallidotomy who did not undergo surgery versus patients with Parkinson's disease who did undergo versus patients with Parkinson's disease who did undergo 461-7.

7 Langston J, Widner I, Goetz C, et al. Core assessment program for intracerebral transplantation (CAPIT). Mov Disord 1992;7:2-13.

8 Siegfried J, Lippitz B. Bilateral chronic electrostimulation of ventroposterolateral pallidum: a new therapeutic approach for alleviating all parkinsonian symptoms. Neurosurgery 1994;35:1126-9.

9 Laitinen LV. CT guided ablative stereotaxis without ventriculography. Appl Neurophysiol 1985;48:18-21.

10 Alterman RL, Kelly P. Magnetic resonance imaging guidance in surgery for Parkinson's disease. In: Germano I, ed. Neurosurgical treatment of movement disorders. Park Ridge, American Association of Neurological Surgeons, 1998:195-205.

11 Favre J, Taha JM, Nguyen TT, et al. Pallidotomy: a survey of current practice in North America. Neurosurgery 1996;39: 883-9.

12 Bakay R. Comments on pallidotomy: a survey of current practice in North America. Neurosurgery 1996;39:891-2.

13 Hariz MI, Fodstad H. The pallidotomy debate: are microelectrode guided pallidotomies always located in the pallidum? Br $\mathcal{F}$ Neurosurg 1998;12:595-7

14 Hughes AJ, Daniel SE, Kilford L, et al. Accuracy of clinical diagnosis of idiopathic Parkinson's disease: a clinicopathological study of 100 cases. F Neurol Neurosurg Psychiatry 1992;55:181-4

15 Talairach J, Szikla G. Atlas of stereotaxic anatomy of the telencephalon: anatomo-radiological studies. Paris: Masson and Cie, 1967.

16 Merello M, Cammarota A, Betti O, et al. Involuntary movements during thermolesion predict a better outcome after microelectrode guided posteroventral pallidotomy. F Neurol microelectrode guided posteroventral pal
Neurosurg Psychiatry 1997;63:210-13.

17 Gross RE, Lombardi WJ, Lang AE, et al. Relationship of lesion location to clinical outcome following microelecrode guided pallidotomy for Parkinson's disease. Brain 1999;122:405-16. 
18 Kishore A, Turnbull IM, Snow BJ, et al. Efficacy, stability and predictors of outcome of pallidotomy for Parkinson's

19 Carroll CB, Scott R, Davies LE, et al. The pallidotomy debate. BrF Neurosurgery 1998;12:146-50.

20 Van Buren JM, Maccubbin DA. An outline atlas of the human basal ganglia with estimation of anatomical variants. F Neurosurg 1962;19:811-39.

21 Starr PA, Vitek JL, DeLong M, et al. Magnetic resonance imaging-based stereotactic localization of the globus pallidus and subthalamic nucleus. Neurosurgery 1999;44:303-14.
22 Alterman RL, Sterio D, Beric A, et al. Microelectrode recording during posteroventral pallidotomy: impact on peurosurgery 1999;44: 15-23.

23 Baron MS, Vitek JL, Bakay RA. et al. Reply to : Lang AE, Lozano A, Tasker R, et al. Neuropsychological and behavioral changes and weight gain after medial pallidotomy. Ann Neurol 1997;41:835-6.

24 Samii A, Turnbull IM, Kishore A, et al. Reassessment of unilateral pallidotomy in Parkinson's disease. A 2 year folow up study. Brain 1999;122:417-25.

\section{HISTORICAL NOTE}

\section{Wallerian degeneration}

Neurologists of the early 19 th century relied on gross anatomy. The development of the compound microscope, techniques for tissue fixation and embedding, and the use of a microtome were essential inventions for the microscopic study of the nervous and other systems. Histology applying these methods to neural tissue was in large part the achievment of Robert Remak ${ }^{1}$ and his former student Rudolph Albert von Kölliker (1817-1905). Until the 1830s, the microscopic anatomy of the neuron, axon, and their connecting processes were not understood. Remak (1838) had noted "primitive bands" that probably were nerve sheaths, but it was Theodor Schwann (1810-82) who first described in 1838 the myelin sheath as a fatty deposit on the inner surface of the structureless cell membrane (called the neurilemma by $\mathrm{Bi}$ chat). By the use of a compound microscope, Remak was able to prepare a histological monograph $^{2}$ on the nervous system. Kölliker's text ${ }^{3}$ included accounts of various forms of nerve cells as well as:

"a good many fine, pale fibres, like the processes of cells,... whether they are nerve tubes or are to be referred to as the processes of cells."

Deiters, in 1865 gave an important account of the nerve cell and its processes"protoplasmic" (dendrites) and "nervous" (axon). He died aged 30 of typhus, but his findings were published in Schultze's book that also included Deiter's account of the vestibular nucleus that commemorates his name.

Before the essential structure of nervous tissue could be shown, specific staining techniques and serial experiments were needed. Carmine was applied with success and used by Joseph von Gerlach in 1858. Niss introduced methylene blue in the same year. Waldeyer used haematoxylin to stain axis cylinders in 1863. The myelin sheath had to await the Carl Weigert stain in 1884. The next year, Vittorio Marchi (1851-1908) with Algeri showed the black, degenerative products of myelin by mordanting with chromium salts and staining with osmic acid.
The demonstration of degenerative processes of the myelin sheath was of course a crucial tool with which to reveal degenerative pathology.

Augustus Volney Waller (1816-70) developed a vital technique in the study of the nervous system. He was born on a Kent farm, but spent his childhood in France, and qualified in Paris (1840). He then practised in Kensington (1842-51) and later went to Europe to become an outstanding experimental physiologist. In 1850 , Waller ${ }^{5}$ reported his findings to the Royal Society. $\mathrm{He}$ showed that if the glossopharyngeal and hypoglossal nerves are cut, the distal segment containing axis cylinders cut off from the nerve cell undergoes degeneration. Since the cell body and proximal stump remained intact for a long period, Waller inferred that the nerve cells nourish nerve fibres. His studies made it possible to trace nerve fibres and their diseases. Combined with Forel's seminal studies, Waller's work was a necessary foundation for the neuron theory:

"It is my intention at present to describe various alterations, as seen under the microscope, which take place in the structure of the same nerves after their continuity with the brain has been interrupted ... at the end of the third or fourth day, we detect the first alteration....about five or six days after section, the alteration of the nerve-tube ... has become much more distinct by a kind of coagulation or curdling of the white substance and axis cylinder ... the disjointed condition ... is greater toward the extremities . . as we ascend toward the brain the disorganisation appears to decrease ... On the 7th, 8 th and 9th days... the curdled particles of medulla become still more disconnected, and in parts are removed by absorption The tubular sheath is also ruptured and disorganised, . . collected into oval or circular coagulated masses ..."

Wallerian degeneration was born and has been inculcated into medical students ever since. Copious references and extracts of these investigations are contained in $\mathrm{McHenry}^{6}$, and in Clarke and O'Malley. ${ }^{7}$

Waller ceased clinical practice in 1851 , returning to Bonn where he worked with Budge on pupillary innervation that he showed derived from the T1-T2 segments (cilio-spinal centre) and the sympathetic trunk that exerted a vasoconstrictor action. He travelled to Paris in 1856 and fell sick, probably with rheumatic fever. He recovered and took the chair of physiology in Birmingham, but further illness hastened retirement. He died with severe angina in 1870 .

His son Augustus D Waller became a distinguished physiologist, who on mention of father's name, remarked: "I am the Wallerian degeneration."

The varied terminations of axons was studied by Willy Kuhne, and Nissl had advanced descriptions of the cell body constituents by using aniline dyes as cell stains. Rudolf Virchow in 1846 first observed the neuroglia, as an elevated membrane of what he realised was connective tissue, beneath the ventricular ependyma.. In 1870, Bernhard Aloys von Gudden (1824-1886), professor of psychiatry at Zurich and later Munich, produced secondary atrophy of the central neural structures by the removal of sensory organs or cranial nerves in young animals. In 1889, he showed the crossed and uncrossed fibres of the optic nerve and the occurrence of secondary atrophy in the thalamus after removal of specific cortical areastransneuronal degeneration.

This vast field of work ${ }^{7}$ culminated in the work of Camillo Golgi ${ }^{8}$ who used silver stains and demonstrated structures previously invisible, which were to be the basis of his axonal net theory that displaced Gerlach's notion of a neural plexus.

I M S PEARCE 304 Beverley Road, Anlaby, Hull HU10 7BG, UK jmspearce@freenet.co.uk

Pearce JMS. Remak, father and son. Lancet 1996;347:1669-70.

2 Remak R. Observationes anatomicae et microscopicae de sytematis nervosi structura. Beroini, Reimerianis, 1838. Cited In: Haymaker W, Schiller F, eds. The founders of neurology. 2nd ed. Springfield, Illinois: Charles C Thomas, 1970: 66-9.

3 Kolliker RA von. Manual of human histology. 2 Vols. Translated by: Busk G, Huxley T. London: Sydenham Society, 1853.

4 Schultze MJS. Untersuchungen uber Gehirn und Ruckenmark des menschen und der Saugethiere. Braunschweig, 1865.

5 Waller AV. Experiments on the section of the glossopharyngeal and hypoglossal nerves of the fros and observations of the alterations produced thereby in the structure of their produced thereby in the structure of their Sci 1850;140:423-9.

6 McHenry LC. Garrison's History of neurology. McHenry LC. Garrison's History of neurology.
Springfield, Illinois: Charles C Thomas, 1969,

7 Clarke E, O'Malley CD. The human brain and spinal cord: a historical study. 2nd ed. San Francisco: Norman, 1996:27-109.

8 Golgi C. Sulla fina anatomia degli organi centrali del sistema nervoso. Milano: U Hoepli, 1886. 